\section{Nit}

$9 / x^{2}$ $4 x=$
1 st

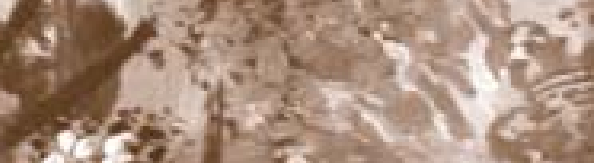

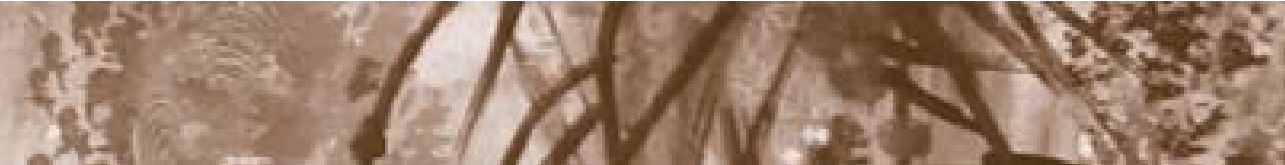

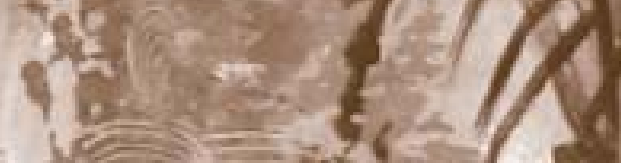

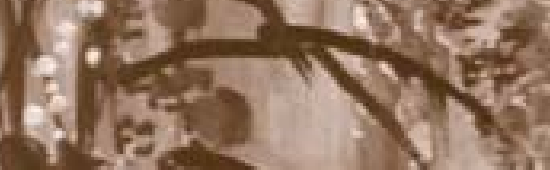

tor

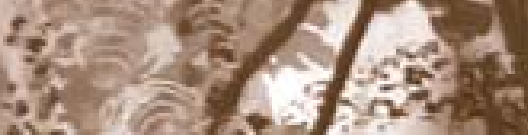

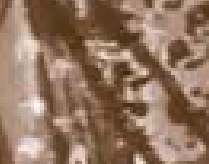

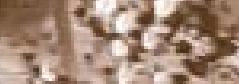

20.

2.

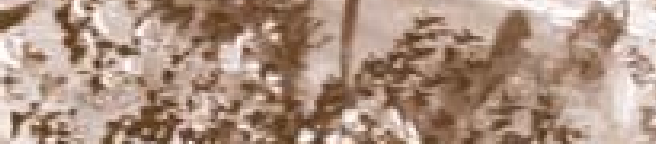

rif toting

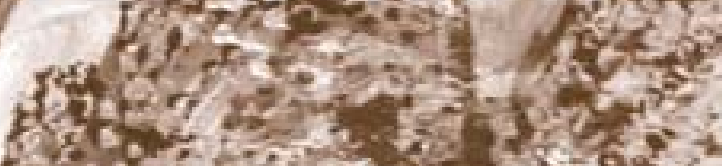

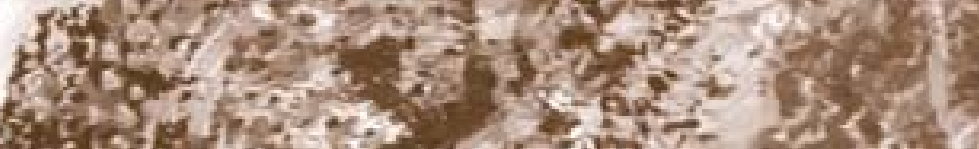

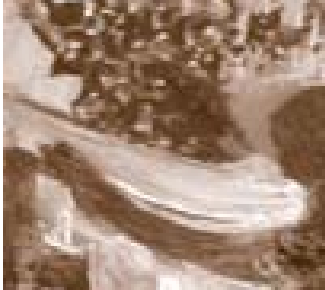

से

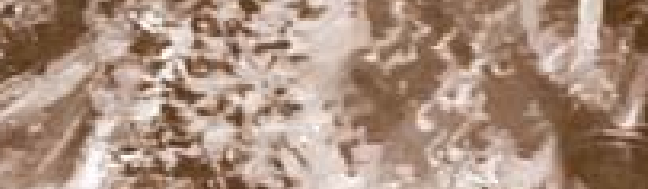

If

Sit:

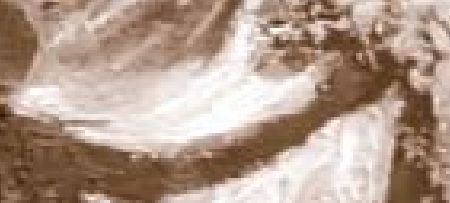
$3 x^{2}$

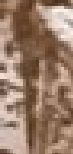
$\sum_{2}^{3}$

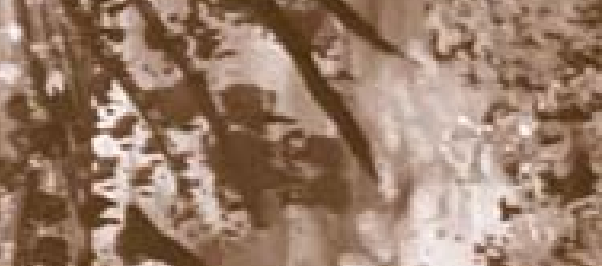
a) $x^{2}+x^{2}$

\section{$2 \times 3$.}

20.5

दो
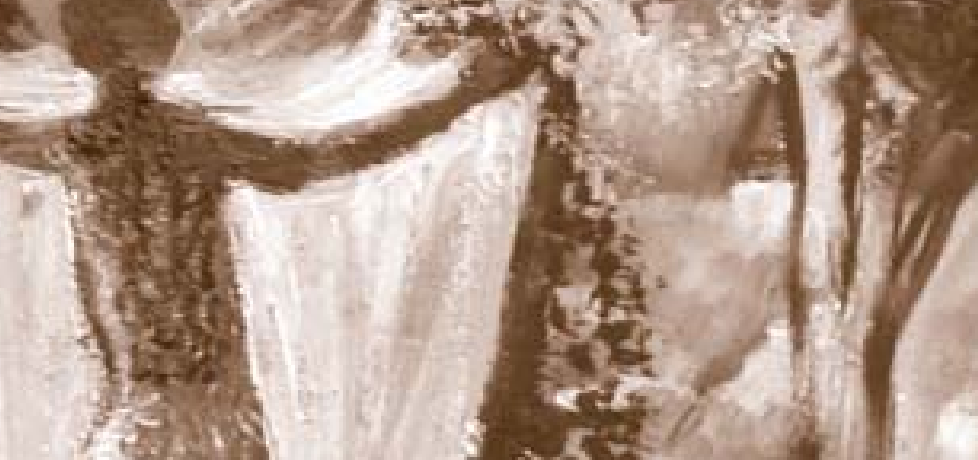

tost?

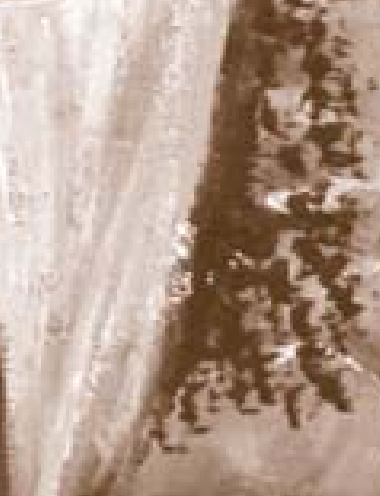

$=$

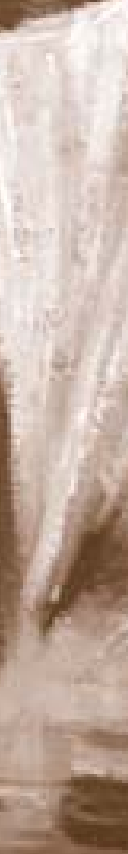

$3=$

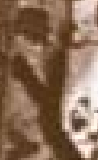

if 


\title{
3 tres enfoques para el estudio de la mortalidad
}

\author{
Lorenzo Herrera leòn, María Victoria Ponce, Jenny Vásquez, Nelson Raudales Garcia, Ulda Borjas García \\ José F. Aguilar Sauceda, Claudio Borjas García, Héctor Baca Santos, Nohemi Borjas Rodríguez \\ Sonia Salguero M olina, Digna América Monge
}

Dentro de las actividades del curso de Interpretación y A nálisis de $D$ atos D emográficos, correspondientes a la M aestría en D emografía Social, ha tocado a los estudiantes, desarrollar tres temas con vínculo muy actual de la realidad hondureña. En forma de artículo 0 ensayo, estos tres breves estudios pretenden presentar y/o promover otros puntos de vistas alternativas y a la vez, complementarios, de los enfoques tradicionales en cuanto al análisis de la mortalidad.

El primero de ellos, Exceso del riesgo de mortalidad infantil de $\mathrm{H}$ onduras respecto a países centroamericanos, ofrece la posibilidad de comparar la situación actual de Honduras en cuanto al exceso de riesgo de mortalidad infantil, con otros países de la región centroamericana; en el mismo, se precisa el lugar que ocupa este país en el ámbito centroamericano, destacando las ventajas rel ativas y desventajas con sus semejantes.

De factura sencilla, sin grandes formulaciones analíticas, su lectura con seguridad nos ubica en un entendimiento más profundo de la realidad centroamericana en cuanto a la mortalidad infantil.

El segundo trabajo, titulado Diferenciales Extremos de la M ortalidad Infantil en $\mathrm{H}$ onduras 2001, introduce una línea de análisis muy peculiar, ya que sintetiza el comportamiento extremo de la tasa de mortalidad infantil, es decir, aborda su estimación en categorías extremas de variables relevantes para su explicación, lo cual brinda la oportunidad de observar el rango de movimiento del índice. Basada en la aplicación de la técnica desarrollada por el profesor inglés W. Brass, para estimar la mortalidad en la niñez, los autores logran poner en evidencia al gunas peculiaridades del comportamiento de una de las variables más importante del cambio poblacional.

En tercer lugar, aparece R elación entre mortalidad infantil y esperanza de vida, una manera no tradicional de medir la influencia que ha tenido el progreso en la disminución de la mortalidad, sobre todo la infantil, en el incremento de la vida media del ciudadano hondureño. Con la aplicación de la novedosa técnica desarrollada por Eduardo A rriaga, en este trabajo se exhiben, las contribuciones 0 aportes hechos por los distintos grupos de edad, a la esperanza de vida al nacimiento entre 1980 y 2000. No cabe ninguna duda de que, en toda la urdimbre de efectos interactivos, es el de los menores de 5 años y especialmente el de menores de un año, el protagonista principal del progreso logrado en 20 años.

Con aciertos y desaciertos, la presentación de esta modesta trilogía se hace con el ánimo de estimular la participación de estudiantes de postgrado, en la imperativa tarea de comunicar resultados, actividad vital para cualquier investigador social.

Profesor Lorenzo I. H errera León

C entro de Estudios Demográficos

U niversidad de La H abana 